\title{
Testing and Performance Analysis of a Hollow Fibre-Based Core for Evaporative Cooling and Liquid Desiccant Dehumidification
}

\author{
M. Jradi ${ }^{1, *}$, S. Riffat ${ }^{2}$
}

${ }^{1}$ Center for Energy Informatics, The Maersk Mc-Kinney Moller Institute, University of

Southern Denmark, 5230 Odense M, Denmark

${ }^{2}$ Institute of Sustainable Energy Technology, Department of Architecture and Built

Environment, University of Nottingham, Nottingham NG7 2RD, UK

*Corresponding author, Email: mir@mmmi.sdu.dk

Phone: +4565508210; Address: Campusvej 55, DK-5230 Odense M, Denmark 


\title{
Testing and Performance Analysis of a Hollow Fibre-Based Core for Evaporative Cooling and Liquid Desiccant Dehumidification
}

\author{
M. Jradi ${ }^{1 *}$, S. Riffat ${ }^{2}$ \\ ${ }^{1}$ Center for Energy Informatics, The Maersk Mc-Kinney Moller Institute, University of \\ Southern Denmark, 5230 Odense M, Denmark \\ ${ }^{2}$ Institute of Sustainable Energy Technology, Department of Architecture and Built \\ Environment, University of Nottingham, Nottingham NG7 2RD, UK \\ *Corresponding author, Email: $\underline{\text { mjr@mmmi.sdu.dk }}$ \\ Phone: +4565508210; Address: Campusvej 55, DK-5230 Odense M, Denmark
}

\begin{abstract}
In this study, an innovative heat and mass transfer core is proposed to provide thermal comfort and humidity control using a hollow fibre contactor with multiple bundles of micro-porous hollow fibres. The hollow fibrebased core utilizes 12 bundles aligned vertically, each with 1000 packed polypropylene hollow fibres. The proposed core was developed and tested under various operating and ambient conditions as a cooling core for a compact evaporative cooling unit and a dehumidification core for a liquid desiccant dehumidification unit. As a cooling core, the fibre-based evaporative cooler provides a maximum cooling capacity of $502 \mathrm{~W}$ with a wet bulb effectiveness of $85 \%$. As a dehumidification core and employing potassium formate as a liquid desiccant, the dehumidifier is capable of reducing the air relative humidity by $17 \%$ with an overall dehumidification capacity of $733 \mathrm{~W}$ and humidity effectiveness of $47 \%$. Being cheap and simple to design with their attractive heat and mass transfer characteristics and the corresponding large surface area-to-volume ratio, hollow fibre membrane contactors provide a promising alternative for cooling and dehumidification applications.
\end{abstract}

Keywords: Hollow fibre membrane; Liquid desiccant dehumidification; Evaporative cooling; Cooling capacity; Effectiveness.

$\begin{array}{ll}\text { Nomenclature } \\ \text { AC } & \text { alternating current } \\ \text { COP } & \text { coefficient of performance } \\ \text { EER } & \text { energy efficiency ratio (Btu/Wh) } \\ \text { h } & \text { enthalpy }(\mathrm{J} / \mathrm{kg}) \\ \mathrm{HCOOK} & \text { Potassium Formate } \\ \mathrm{LiBr} & \text { Lithium Bromide } \\ \mathrm{LiCl} & \text { Lithium Chloride } \\ \dot{\mathrm{m}} & \text { mass flow rate }(\mathrm{kg} / \mathrm{s}) \\ \mathrm{P}_{\mathrm{v}} & \text { vapour pressure }(\mathrm{mbar}) \\ \mathrm{PE} & \text { polyethylene } \\ \mathrm{PEI} & \text { polyetherimide } \\ \mathrm{PP} & \text { polypropylene } \\ \mathrm{PTFE} & \text { polytetrafluoroethylene } \\ \mathrm{PVC} & \text { polyvinyl chloride } \\ \mathrm{PVDF} & \text { polyvinylidene fluoride } \\ \mathrm{RH} & \text { relative humidity }(\%) \\ \mathrm{LiCl} & \text { Lithium Chloride } \\ \dot{\mathrm{Q}} & \text { cooling capacity }(\mathrm{W}) \\ \mathrm{T} & \text { temperature }\left({ }^{\circ} \mathrm{C}\right) \\ \mathrm{W} & \text { humidity ratio }\left(\mathrm{kg} \mathrm{H} 2 \mathrm{O} / \mathrm{kg}_{\mathrm{air}}\right) \\ \dot{\mathrm{W}} & \text { electric power }(\mathrm{W}) \\ & \\ \text { Greek } & \\ \varepsilon & \text { effectiveness }\end{array}$




$\begin{array}{ll}\text { Subscripts } & \\ \text { a } & \text { air } \\ \text { db } & \text { dry bulb } \\ \text { Deh } & \text { dehumidification } \\ \text { dp } & \text { dew point } \\ \text { ele } & \text { electric } \\ \text { eq } & \text { equilibrium } \\ \text { in } & \text { input } \\ \text { out } & \text { output } \\ \text { su } & \text { supply } \\ \text { wb } & \text { wet bulb }\end{array}$

\section{Introduction}

As an alternative and environmentally friendly cooling technology, evaporative cooling has a large potential to provide thermal comfort in occupied spaces due to the simple design, cheap materials and high coefficient of performance in addition to the efficient operation compared to conventional vapour compression-based cooling systems (Delfani et al. 2010; Hammoud, Ghali and Ghaddar 2014; Maheshwari, Al-Ragom and Suri 2001; Uçkan et al. 2013). Evaporative cooling systems have a coefficient of performance in the range of $8-20$ which is much higher than that of the conventional vapour compression coolers, and thus requiring less electrical power to operate providing high economic feasibility (Anisimov, Pandelidis, and Danielewicz 2014; Cui et al. 2014; Zhan et al. 2011). In addition, such evaporative cooling systems can avoid $44 \%$ of the carbon dioxide emissions produced by vapour compression systems with a very high energy efficiency ratio (EER) reaching 80 (Duan et al. 2012). As a comparison, typical values of EER for different air conditioning techniques are presented in Table 1 (Afonso 2006). However, conventional evaporative coolers such as those disclosed in US Patents No. 5,971,370 and 6,079,365 (Galabinski 1999; Medlin and Wilkins 2000), supply water vertically through multiple pads allowing water evaporation and process air cooling. Such evaporative coolers are relatively expensive to manufacture and install and have major drawbacks with a high possibility of drawing water through the pads into the building's interior. This will have negative impacts on the building structure and the indoor air quality including damage to adjacent equipment, high rates of microbial growth and joint and respiratory infections. Nevertheless, high air relative humidity in buildings affects the occupants breathing and skin evaporation rate, in addition to encouraging mould and germs growth and building construction and 
equipment decay. Thus it is favourable to remove water vapour from air through dehumidification. Conventional cooling systems, mainly vapour compression units, are extensive energy consumers using cold coils to reduce air temperature below the dew point temperature allowing water vapour condensation and latent heat release. Recently, a large body of research has been presented regarding the use of solid and liquid desiccant materials and their potential in air dehumidification and cooling applications (Kumar, Chaudhary and Yadav 2014; Mei and Dai 2008; Qiu and Riffat 2010; Uçkana et al. 2014). The major factor governing moisture absorption by a desiccant material is process airdesiccant material surface vapour pressure gradient. As the vapour pressure of the desiccant surface is less than that of the air, moisture absorption continue allowing air dehumidification until the equilibrium in the vapour pressure between air and desiccant is attained (Lownestein 2008). Liquid desiccant air dehumidification units have significant potential providing different advantages compared to solid desiccant units including lower consumption of energy, higher coefficient of performance, higher flexibility with the ability to transport the liquid desiccant between various system units including the dehumidifier and regenerator (She, Yin and Zhang 2014; Daou, Wang and Xia 2006; Oliveira et al. 2000; Qi, Lu and Huang 2014; Yutong and Hongxing 2010). On the other hand, conventional liquid desiccant units still suffer from major drawbacks especially the serious problem of liquid desiccant entrainment by the process air which could affect the indoor air quality and has negative impacts on the thermal comfort of the occupants (Jradi and Riffat 2014). Therefore, it is reported that using semi-permeable micro-porous contactors in liquid desiccant units could help in eliminating the liquid desiccant entrainment problem (Isetti, Nannei, and Magrini 1997). In order to address these issues and to improve the indoor air quality, we are proposing an innovative dehumidification and cooling system using hollow fibres and employing liquid desiccant as the dehumidification working fluid. Compared to the conventional cooling and dehumidification techniques, the proposed system has the following innovative features:

- Providing thermal comfort through the use of selective hollow fibres, with high packing density and large heat and mass transfer surface area, allowing no direct contact between air and liquid desiccant and thus no droplets carryover by the air. 
- Employing environmentally friendly working fluids, water and potassium formate liquid desiccant, to reduce the environmental negative impacts of space air conditioning.

- Presenting an innovative evaporative cooling core using hollow fibre membrane as a wetting medium with no water-air interaction and thus better indoor air quality.

- Using inexpensive materials, hollow fibres and cheap containers in addition to the simple and compact integrated system configuration, resulting into low system capital and running costs.

\section{Hollow Fibre Contactor Technology}

A hollow fibre contactor is composed of bundles of micro-porous hollow fibre membranes having numerous fine pores across the fibre wall with a very small diameter (Gabelman and Hwang 1999). Hollow fibre-based membranes, shown in Fig. 1 (SpinTek), have the ability to act as a passive barrier between two heterogonous fluid phases without dispersion, where one of those fluids occupies the pores void volume on the surface of the membrane. Hollow fibre contactors are typically made of materials with high hydrophobic effect including: polyethylene (PE), polypropylene (PP), polytetrafluoroethylene (PTFE) and polyvinylidene fluoride (PVDF) (Rajabzadeh et al. 2009). Different companies now are manufacturing hollow fibre membrane contactors as an economic and cost effective alternative solution in different fields as shown in Fig. 2 (Mitsubishi). Employing cheap materials and having attractive mass transfer characteristics in addition to their large surface area/volume ratio, hollow fibres have been successfully employed as membrane contactors in various applications including: chemical engineering separation, liquid-liquid extraction, gas absorption, microfiltration processes, brackish water desalination, potable water purification, wastewater treatment, drying processes and biofuels separation (Boributh et al. 2012; Cath et al. 2005; Mansourizadeh and Ismail 2009).

The selection of the hollow fibre membrane contactor for a specific application is based on different factors including fibre surface pore size, surface pores distribution, separation layer thickness in addition to the physical, chemical and mechanical properties of the fibre material (Peng et al. 2012). Pabby and Sastre (2013) presented a comprehensive review on the recent research and developments in the field of hollow fibre contactor technology and membrane-based extraction processes. They 
reviewed different hollow fibre membrane aspects including performance, mass transfer modelling, stability issues, applications and the development in the hollow fibre membrane-based separation techniques. In addition to the commercial advancement in the field of hollow-fibre based membrane contactors, different researchers have investigated the performance of such type of contactors employing different configurations and fluid flow patterns, with specific concentration on the heat and mass transfer phenomena within the hollow fibre membrane (Bui, Vu, and Nguyen 2010; Huang et al. 2013; Huang and Yang 2013; Zhang et al. 2012). Very few research studies have investigated the use of hollow fibres in cooling and dehumidification applications. A theoretical and experimental study of a liquid desiccant air dehumidification system utilizing a hollow-fibre based membrane core was presented by Zhang and Zhang (2014). A compression heat pump was used to simultaneously heat and cool the liquid desiccant solution to enhance the system efficiency by passing the solution through the heat pump evaporator and condenser. A dehumidification efficiency of 0.3-0.5 was attained and a satisfactory system performance was reported even in hot and humid conditions. Dijkink et al. (2004) carried out an experimental investigation of polyetherimide (PEI) hollow fibre membrane contactor coated with a thin non-porous silicone layer on the inside and using dilute aqueous glycerol solution as a liquid desiccant. Johnson, Yavuzturk, and Pruis (2003) investigated experimentally hollow fibre based evaporative cooling systems and recommended the use of hollow fibre membranes with larger pore sizes, thinner membrane walls and low tortuosity to increase mass transfer rates in evaporative cooling systems. Das and Jain (2013) studied the performance of air-liquid indirect membrane contactors for liquid desiccant cooling systems using hollow fibres. The maximum vapour flux attained was about $1295 \mathrm{~g} / \mathrm{m}^{2} . \mathrm{h}$ with dehumidification effectiveness between $23 \%$ and $45 \%$ using $\mathrm{LiCl}$ as a desiccant solution. Based on these analytical and numerical investigations and the results reported, it is shown that hollow fibre-based membrane contactors have favourable heat and mass transfer characteristics and possess a large potential to serve dehumidification and cooling applications. 


\section{Proposed Hollow-Fibre Based Core}

Having favourable hydrophobic specifications, large surface area-to-volume ratio, attractive heat and mass transfer characteristics, simple and maintenance-free operation, in addition to employing cheap materials that are corrosion resistant and high-temperature and pollution tolerant, hollow fibre-based membrane presents a cost effective and environmentally friendly alternative solution to serve as a core in evaporative cooling systems and liquid desiccant dehumidification systems. In this work an innovative hollow fibre-based core is proposed to provide thermal comfort and humidity control and improve indoor air quality in occupied spaces. The presented core consists mainly of a hollow fibrebased membrane contactor that could be employed as a dehumidification core in liquid desiccant dehumidification units and as a cooling core in evaporative cooling units. As shown in Fig. 3, the hollow fibre-based core utilizes 12 bundles aligned vertically, each with 1000 packed hollow fibres. The specifications of the hollow fibres utilized in the study are presented in Table 2 .

The fibres are assembled and packed using short pieces of a plastic tube and potted at both ends of the bundle using epoxy resin and silicone sealant as shown in Fig. 4(a). In addition, the fibre bundles are attached to the plastic water/liquid desiccant distribution network at the top of the unit as shown in Fig. 4(b). Water/liquid desiccant is circulated in the system and a small pump (6 W electric power consumption), shown in Fig. 5(a) is utilized to feed the fluid from a plastic collection tank, placed at the bottom of the cooling unit, through a pipe connected to the 12 fibre bundles. Water/liquid desiccant is circulated at a flow rate ranging between 0.2 and $0.7 \mathrm{l} / \mathrm{min}$ where the fluid flows through hollow fibres and drops back into the collection tank. An air duct is employed where fibres are densely spread inside and extend through both ends of the duct. Air is introduced employing a small AC blower, shown in Fig. 5(b), through the duct in a horizontal direction to the vertical fluid flow pattern in the fibre membrane.

The developed hollow fibre-based core configuration allows cross-flow heat and mass exchange between the air flow in the duct and fluid flow in the hollow fibres. The semi-permeable membrane hollow fibres employed are water vapour permeable and liquid tight, allowing moisture transport with no direct contact between the liquid flowing inside the fibres and the air passing across the external 
fibres surface. The mass transport of water vapour depends mainly on the water vapour pressure difference between both sides of the fibre membrane wall. When used as a dehumidifier, the humid air is introduced through the duct and gets in contact with the external surface of the fibres, where the liquid desiccant flows inside the fibres absorbing water vapour through the pores distributed along the surface and dehumidifying the process air. Similarly when the core is utilized as an evaporative cooler, hot air is introduced to flow in the duct where water flows inside the fibres, and a portion of the water is evaporated leading to a drop in the air temperature. The large surface area-to-volume ratio provided by the compact and simple design of the fibre membrane enhances heat and mass transfer between the air flowing on the membrane external surface and the fluid flowing inside the hollow fibres. Neither water nor liquid desiccant carryover occurred during cooling and dehumidification processes providing thermal comfort and good indoor air quality.

In the following sections, the preliminary testing of the fibre membrane-based core as an evaporative cooler and as a liquid desiccant dehumidification unit is presented and the results are reported.

\section{Evaporative Cooling Unit Performance}

The hollow fibre-based core developed and was tested and investigated as a cooling core for a compact evaporative cooling unit. A climatic chamber was utilized to control the inlet temperature and relative humidity to the cooling core. In addition, two HMP50 temperature and humidity probes were employed to record the intake air and supply air humidity and temperature. The temperature measurement range of these sensors is -40 to $+60^{\circ} \mathrm{C}$ with $\pm 0.3^{\circ} \mathrm{C}$ accuracy where the relative humidity measurement range is 0 - $98 \%$. In addition, a K-type thermocouple of $\pm 0.25 \%$ accuracy and a maximum temperature measurement of $250^{\circ} \mathrm{C}$, was employed to measure the water inlet temperature to the fibre membrane. The recording sensors were connected to a Datataker DT 80 data logger for data monitoring and recording. Throughout the cooling unit preliminary testing sessions, intake air speed of $2.4 \mathrm{~m} / \mathrm{s}$ was employed.

The overall cooling capacity of the evaporative cooling unit can be given by:

$$
\dot{Q}_{\text {cooling }}=\dot{m}_{s u}\left(h_{i n}-h_{s u}\right)
$$


$\dot{m}_{\text {su }}$ is the supply air mass flow rate in $\mathrm{kg} / \mathrm{s}, h_{\text {in }}$ and $h_{\text {out }}$ are the respective air specific enthalpy at the inlet and outlet of the evaporative cooler.

The cooler coefficient of performance is given by the ratio of the cooling capacity provided to the electric power consumption. The total electric power consumption, $\dot{W}_{\text {ele,cooler }}$ in $\mathrm{W}$, includes the power required to operate the water circulation pump for and the power required to run the fan employed for air supply. The system overall COP is represented by:

$$
C O P_{\text {cooler }}=\frac{\dot{Q}_{\text {cooling }}}{\dot{W}_{\text {ele,cooler }}}
$$

The cooling effectiveness of the evaporative cooler can be expressed in terms of the wet bulb effectiveness and the dew point effectiveness given by equations (3) and (4) respectively.

$$
\begin{gathered}
\varepsilon_{w b}=\frac{T_{i n, d b}-T_{s u, d b}}{T_{i n, d b}-T_{i n, w b}} \\
\varepsilon_{d p}=\frac{T_{i n, d b}-T_{s u, d b}}{T_{i n, d b}-T_{i n, d p}}
\end{gathered}
$$

$T_{i n, d b}$ is the inlet air dry bulb temperature, $T_{s u, d b}$ is the supply air dry bulb temperature, $T_{i n, w b}$ is the inlet air wet bulb temperature and $T_{i n, d p}$ is the inlet air dew point temperature.

\subsection{Climatic Chamber Set Temperature of $30^{\circ} \mathrm{C}$}

Figure 6(a) presents the variation in the inlet and outlet air temperatures across the evaporative cooler employing different water volumetric flow rates. Based on the data recorded, the average temperature drop across the cooler is about $6.1^{\circ} \mathrm{C}, 6.9^{\circ} \mathrm{C}$ and $6.7^{\circ} \mathrm{C}$ for water volumetric flow rate of $0.2,0.4$ and 0.5 1/min respectively. In addition, Fig. 6(b) presents the variation in the inlet and outlet air relative humidity at different flow rates. It is shown that the average increase in the outlet air relative humidity is about $22.6 \%, 24.5 \%$ and $24.6 \%$ at water volumetric flow rate of $0.2,0.4$ and $0.51 / \mathrm{min}$.

Figure 7(a) shows the variation in the cooling capacity delivered by the evaporative cooler and the cooler coefficient of performance (COP) at different water volumetric flow rates. The maximum cooling capacity produced by the system increases from $164 \mathrm{~W}$ at $0.2 \mathrm{l} / \mathrm{min}$ water volumetric flow rate to about $191 \mathrm{~W}$ at $0.5 \mathrm{l} / \mathrm{min}$ volumetric flow rate. Correspondingly, the COP increases from an 
average of 5.3 to about 6.3 as the water volumetric flow rate increases from 0.2 to $0.51 / \mathrm{min}$. In addition, the estimated wet bulb and dew point effectiveness of the system is presented in Fig. 7(b). It is shown that the wet bulb effectiveness increases from $64 \%$ to $69 \%$ with the increase of volumetric flow rate of water from 0.2 to $0.51 / \mathrm{min}$, accompanied with an increase in the dew point effectiveness from $41 \%$ to $46 \%$.

\subsection{Climatic Chamber Set Temperature of $35^{\circ} \mathrm{C}$}

Increasing the climatic chamber set temperature from $30^{\circ} \mathrm{C}$ to $35^{\circ} \mathrm{C}$, Fig. 8 (a) shows the variation in the inlet and outlet air temperatures across the evaporative cooler As shown in the figure, the maximum temperature drop across the cooler is about $7.7^{\circ} \mathrm{C}, 8.2^{\circ} \mathrm{C}$ and $8.9^{\circ} \mathrm{C}$ for water volumetric flow rate of $0.4,0.5$ and $0.7 \mathrm{l} / \mathrm{min}$ respectively. In addition, Fig. $8(\mathrm{~b})$ shows the variation in the inlet and outlet air relative humidity at different flow rates. It is reported that the average increase in the outlet air relative humidity is about $22.3 \%, 23.2 \%$ and $26.1 \%$ at water volumetric flow rate of $0.4,0.5$ and $0.7 \mathrm{l} / \mathrm{min}$.

Figure 9(a) presents the cooling capacity produced by the evaporative cooler and the cooler COP at different water volumetric flow rates. It is shown that the maximum cooling capacity produced by the system increases from $278 \mathrm{~W}$ at $0.4 \mathrm{l} / \mathrm{min}$ water volumetric flow rate to about $334 \mathrm{~W}$ at $0.7 \mathrm{l} / \mathrm{min}$ volumetric flow rate. The evaporative cooler $\mathrm{COP}$ follows an increasing trend as the water volumetric flow rate increases. As shown in the figure, the maximum COP attained increases from 10.7 to 12.9 as the volumetric flow rate increases from 0.4 to 0.7 1/min. Moreover, the evaporative cooler wet bulb and dew point effectiveness data is presented in Fig. 9(b). The system maximum wet bulb effectiveness increases from $71 \%$ to $79 \%$ as the water volumetric flow rate increases from 0.4 to 0.7 1/min. Similarly, the system dew point effectiveness increases from $50 \%$ to $57 \%$.

\subsection{Climatic Chamber Set Temperature of $45^{\circ} \mathrm{C}$}

With a climatic chamber set temperature at $45^{\circ} \mathrm{C}$, Fig. 10 (a) presents the variation in the evaporative cooler inlet and outlet air temperatures at different water volumetric flow rates. It is shown that the maximum temperature drop across the cooler is about $8.2^{\circ} \mathrm{C}, 8.7^{\circ} \mathrm{C}$ and $9.2^{\circ} \mathrm{C}$ for water volumetric flow rate of 0.2, 0.4 and 0.5 1/min respectively. In addition, Fig. 10(b) shows the variation in the inlet and outlet air relative humidity at different flow rates. The average increase in the relative humidity of 
the supply air is about $22.2 \%, 23.3 \%$ and $24.5 \%$ at water volumetric flow rate of $0.2,0.4$ and 0.5 $1 / \mathrm{min}$.

Figure 11(a) shows the evaporative cooler cooling capacity in addition to the COP employing different water volumetric flow rates and at a climatic chamber set temperature of $45^{\circ} \mathrm{C}$. As the volumetric flow rate of water increases from 0.2 to $0.51 / \mathrm{min}$, the maximum system cooling capacity increases form $427 \mathrm{~W}$ to $502 \mathrm{~W}$. The COP follows a similar trend and increases from 16.1 to a maximum of 19.3 at water volumetric flow rate of 0.2 and $0.5 \mathrm{l} / \mathrm{min}$ respectively. In addition, the system calculated wet bulb effectiveness increases from $78 \%$ to $85 \%$ with the increase of water volumetric flow rate from 0.2 to $0.5 \mathrm{l} / \mathrm{min}$, accompanied by an increase in the dew point effectiveness from $60 \%$ to $65 \%$.

\subsection{Effect of Inlet Air Temperature}

Employing the climatic chamber to control the inlet air temperature to the evaporative cooler allows investigating the impact of inlet air temperature on the overall performance of the cooling system. As presented in the previous sections, three different chamber set temperatures were employed, $30^{\circ} \mathrm{C}$, $35^{\circ} \mathrm{C}$ and $45^{\circ} \mathrm{C}$. Figure 12 (a) shows the variation in the temperature of the inlet air and outlet air of the cooling system at different set temperatures, employing water volumetric flow rate of $0.5 \mathrm{l} / \mathrm{min}$. It is shown that the maximum temperature drop across the evaporator is about $7.2^{\circ} \mathrm{C}, 8.1^{\circ} \mathrm{C}$ and $9.1^{\circ} \mathrm{C}$ at an operating air inlet temperature of $30^{\circ} \mathrm{C}, 35^{\circ} \mathrm{C}$ and $45^{\circ} \mathrm{C}$ respectively. In addition, Fig. 12 (b) shows the variation in the cooling capacity delivered by the evaporative cooler and the COP of the cooling system employing different inlet air temperatures. It is shown that the cooling capacity produced by the system is directly proportional to the inlet air temperature. The maximum evaporative cooler cooling capacity increases from about $191 \mathrm{~W}$ at a set temperature of $30^{\circ} \mathrm{C}$ up to $502 \mathrm{~W}$ at a set temperature of $45^{\circ} \mathrm{C}$. In addition, the system COP follows the same trend as the cooling capacity and increases with the increase in the inlet air temperature. As shown in Fig. 12(b), the evaporative cooler maximum COP is about $7.4,11.2$ and 19.3 at a set inlet air temperature of $30^{\circ} \mathrm{C}, 35^{\circ} \mathrm{C}$ and $45^{\circ} \mathrm{C}$. Regarding the water temperature, Fig. 12(c) shows the variation in the water temperature during the evaporative cooler operation at different inlet air set temperatures. As the water, initially at a temperature between $18-20^{\circ} \mathrm{C}$, is recirculated from the tank to the fibres and then back to the tank, its 
temperature increases with time when it gets in contact with the relatively hot air. As shown in the figure, there is a slight increase from $18.7^{\circ} \mathrm{C}$ to $19.1^{\circ} \mathrm{C}$ in the water temperature when the inlet air has a temperature in the range of $30^{\circ} \mathrm{C}$. However the water temperature increase is much more significant, increasing from about $19.2^{\circ} \mathrm{C}$ to $23.6^{\circ} \mathrm{C}$, employing an inlet air of temperature $45^{\circ} \mathrm{C}$. It is shown that the cooling capacity delivered by the evaporative cooling system and coefficient of performance are inversely proportional to the inlet water temperature. Therefore, to attain the system maximum cooling capacity, the inlet water temperature needs to be maintained at $18-19^{\circ} \mathrm{C}$ throughout the operation period. This could be done through replenishing the water introduced to the fibre-based evaporative cooling system or using a continuous water supply source.

\section{Dehumidification Unit Performance}

In addition to investigating the developed hollow fibre-based core as a cooling core for indirect evaporative cooling applications, the hollow fibre membrane was investigated and tested as a dehumidification core for a liquid desiccant dehumidification unit. The same experimental setup described in section 3 is employed but potassium formate HCOOK liquid desiccant of $74 \%$ mass concentration was circulated and introduced to the fibre membrane instead of water. Potassium formate was used due to its various environmental, physical and thermodynamic advantages compared to conventional liquid desiccants $(\mathrm{LiCl}, \mathrm{LiBr})$ with lower density, viscosity and being less corrosive (Longo and Gasprella 2005; Riffat, James and Wong 1998). Humid air was drawn in the duct from the climatic chamber to be dehumidified by the action of the fibre bundles. Throughout the dehumidification unit preliminary testing sessions, intake air speed of $2.6 \mathrm{~m} / \mathrm{s}$ was employed.

The dehumidification capacity of the liquid desiccant dehumidification system can be represented as:

$$
\dot{Q}_{D e h}=\dot{m}_{s u}\left(h_{a, \text { in }}-h_{a, \text { out }}\right)
$$

$h_{a, i n}$ and $h_{a, o u t}$ are the respective air specific enthalpy at the inlet and outlet of the dehumidification unit. The humidity effectiveness $\left(\varepsilon_{w}\right)$ of the liquid desiccant dehumidification system, is the actual air humidity ratio change over the maximum possible change:

$$
\varepsilon_{w}=\frac{w_{a, \text { in }}-w_{a, \text { out }}}{w_{a, \text { in }}-w_{e q}}
$$


$w_{a, \text { in }}$ and $w_{a, \text { out }}$ are the respective air humidity ratio at the inlet and outlet of the dehumidification unit. $w_{e q}$ is the air humidity ratio in equilibrium with the liquid desiccant in $\mathrm{kg}_{\mathrm{H} 2 \mathrm{O}} / \mathrm{kg}_{\text {air }}$. This humidity ratio is the ideal minimum level to which air can be dehumidified and is given in terms of the desiccant partial vapour pressure $P_{v}$ by equation (7):

$$
w_{e q}=0.62197 \frac{P_{v}}{1.013 \times 10^{5}-P_{v}}
$$

The enthalpy effectiveness $\left(\varepsilon_{h}\right)$ is defined as the actual change in air enthalpy over the maximum ideal enthalpy change and can be given by:

$$
\varepsilon_{h}=\frac{h_{a, \text { in }}-h_{a, o u t}}{h_{a, \text { in }}-h_{e q}}
$$

$h_{e q}$ in $\mathrm{J} / \mathrm{kg}$, is the air enthalpy in equilibrium with the liquid desiccant and can be obtained in terms of the air equilibrium humidity ratio $w_{e q}$ at an air temperature equivalent to that of the liquid desiccant employed.

\subsection{Set Conditions: $\mathrm{T}_{\text {ain }} 30^{\circ} \mathrm{C}$ and $\mathrm{RH}_{\text {ain }} 80 \%$}

Employing climatic chamber settings of $30^{\circ} \mathrm{C}$ temperature and $80 \%$ relative humidity, Fig. 13(a) shows the variation in the air temperature at the inlet and outlet sections of the dehumidifier in addition to the change in the potassium formate liquid desiccant temperature introduced to the hollow fibres-based system. With the inlet air temperature fixed at about $30^{\circ} \mathrm{C}$, the minimum air temperature attained at the outlet of the dehumidifier is about $27.6^{\circ} \mathrm{C}$ where the maximum drop in the air temperature across the dehumidifier is about $2.4^{\circ} \mathrm{C}$. In addition, the liquid desiccant temperature increases with time from $19.3^{\circ} \mathrm{C}$ to about $26.4^{\circ} \mathrm{C}$. This temperature increase is mainly due to the temperature difference between the relatively colder liquid desiccant flowing inside the hollow fibres and the relatively hotter air flowing in direct contact with the external surfaces of the fibres. In addition, the temperature drop across the dehumidifier is inversely proportional to the increase in the liquid desiccant temperature as shown in Fig. 13(a). Fig. 13(b) shows the variation in the relative humidity of air at the inlet and outlet of the dehumidifier. While fixing the inlet air relative humidity at around $80 \%$, the average relative humidity of the outlet air is around $66.1 \%$. The maximum drop in the air relative humidity across the dehumidifier is about $16.6 \%$. In addition, Fig. 13(c) presents the 
variation of the air enthalpy at the inlet and outlet of the dehumidifier along with the cooling capacity delivered by the system. It is shown that the average inlet and outlet air enthalpy is about $85.5 \mathrm{~kJ} / \mathrm{kg}$ and $69.4 \mathrm{~kJ} / \mathrm{kg}$ respectively, where the maximum cooling capacity provided by the dehumidifier is about $733 \mathrm{~W}$ with an average capacity of $673 \mathrm{~W}$ throughout the experimental session. Fig. 13(d) shows the variation in the system humidity and enthalpy effectiveness along with the variation in the liquid desiccant temperature. It is obvious that the dehumidification system effectiveness is inversely proportional to the liquid desiccant temperature. The maximum humidity and enthalpy effectiveness attained is about $47 \%$ and $44 \%$ respectively.

\subsection{Effect of Inlet Air Relative Humidity}

Employing the climatic chamber, multiple testing sessions for the liquid-based dehumidification system was carried out to investigate the effect of the inlet air relative humidity on the overall system performance. Figure 14(a) shows the variation in the air relative humidity at the inlet and outlet of the dehumidifier at three inlet air relative humidity settings, $60 \%, 70 \%$ and $80 \%$. It is shown that the drop in the air relative humidity is directly proportional to the relative humidity of the inlet air, with a maximum drop of $4.9 \%, 9.3 \%$ and $16.3 \%$ at inlet air relative humidity of $60 \%, 70 \%$ and $80 \%$ respectively. In addition, the average air relative humidity at the outlet of the dehumidifier is about $56 \%, 62 \%$ and $66 \%$ for a respective inlet air relative humidity of $60 \%, 70 \%$ and $80 \%$. In addition, Fig. 14(b) presents the variation in the dehumidification system cooling capacity in addition to the variation of the liquid desiccant temperature at the three investigated relative humidity settings. The maximum cooling capacity delivered by the dehumidification system is about $426 \mathrm{~W}, 519 \mathrm{~W}$ and 733 W for relative humidity setting of $60 \%, 70 \%$ and $80 \%$. It is shown that the dehumidification capacity decreases as the temperature of the liquid desiccant increases, where the system cooling capacity is directly proportional to the inlet air relative humidity. Similarly, the dehumidification system humidity effectiveness and enthalpy effectiveness is directly proportional to the inlet air relative humidity as shown in Fig. 14(c). The maximum reported wet bulb and dew point effectiveness are $(40 \%, 37 \%),(43 \%, 40 \%)$ and $(47 \%, 44 \%)$ at inlet air relative humidity setting of $60 \%, 70 \%$ and $80 \%$ respectively. 


\subsection{Effect of Inlet Air Temperature}

Testing sessions were carried out to investigate the effect of inlet air temperature on the dehumidifier various performance parameters. Figure 15(a) shows the variation in the air temperature at the dehumidifier inlet and outlet at two inlet air temperature settings: $30^{\circ} \mathrm{C}$ and $35^{\circ} \mathrm{C}$, where the set relative humidity is fixed at $80 \%$. As shown in the figure, the average air temperature drop across the dehumidifier is about $1.6^{\circ} \mathrm{C}$ and $1.1^{\circ} \mathrm{C}$ at $30^{\circ} \mathrm{C}$ and $35^{\circ} \mathrm{C}$ inlet air set temperature. It is shown that the drop in the air temperature decreases with time due to the fact that the liquid desiccant temperature introduced increases with time. This effect is more significant at higher air temperatures where the desiccant temperature exhibits fast increase compared to relatively lower temperatures.

In addition, Fig. 15(b) shows the variation in the air relative humidity across the dehumidifier under the two employed inlet air temperature settings. It is shown that the relative humidity drop across the dehumidifier is inversely proportional to the inlet air temperature. The average relative humidity drop across the dehumidifier is about $11.5 \%$ and $14.6 \%$ at $30^{\circ} \mathrm{C}$ and $35^{\circ} \mathrm{C}$ respectively. Figure $15(\mathrm{c})$ shows the variation in the liquid desiccant temperature and the cooling capacity delivered by the fibre-based dehumidification system at two different inlet air temperature settings. It is shown that the liquid desiccant temperature increases from $19.3^{\circ} \mathrm{C}$ to $26.4^{\circ} \mathrm{C}$ at inlet air temperature setting of $30^{\circ} \mathrm{C}$, where the desiccant temperature increase rate is more significant at an inlet air temperature setting of $35^{\circ} \mathrm{C}$, increasing form about $21.4^{\circ} \mathrm{C}$ to about $30.9^{\circ} \mathrm{C}$. In addition, it is shown that the dehumidification system cooling capacity is inversely proportional to the inlet air temperature where the average cooling capacity attained is around $673 \mathrm{~W}$ and $612 \mathrm{~W}$ at inlet air temperature setting of $30^{\circ} \mathrm{C}$ and $35^{\circ} \mathrm{C}$ respectively. In addition, it is shown that the system cooling capacity follows a decreasing trend as the liquid desiccant temperature increases. This is due to the liquid desiccant recirculation from the tank to the fibre-based dehumidification system and then back to the tank allowing the increase in the potassium formate temperature. Moreover, Fig. 15(d) shows the effect of the inlet air temperature on the dehumidification system effectiveness. It is shown that increasing the inlet air temperature setting from $30^{\circ} \mathrm{C}$ to $35^{\circ} \mathrm{C}$ is accompanied by a decrease in the system humidity effectiveness from $47 \%$ to $32 \%$ and a decrease in the enthalpy effectiveness from $44 \%$ to $29 \%$. 


\section{Conclusion}

With the increase in the conventional fuel prices and the global warming problem, a growing body of research has been presented to investigate efficient and environmentally friendly alternative technologies and solutions to provide thermal comfort and good indoor air quality. In this work, an innovative hollow fibre-based energy core is proposed and investigated to provide thermal comfort and humidity control in air-conditioned spaces. The presented core comprises a hollow fibre contactor having multiple bundles of micro-porous hollow fibres packed and assembled together, providing large surface area-to-volume ratio with favourable heat and mass transport characteristics. The employed fibre membrane is cheap, simple and compact in design and corrosion resistant with good hydrophobic properties. The use of the innovative semi-permeable fibre-based membrane eliminates any water or liquid desiccant droplets carryover by the air allowing better indoor air quality. The proposed fibre-based core was tested in the Built Environment laboratories at the University of Nottingham to serve as a cooling core in evaporative cooling systems and a dehumidification core in liquid desiccant systems. As a cooling core, the maximum cooling capacity provided by the fibrebased evaporative cooler was about $502 \mathrm{~W}$ with a COP of around 19, wet bulb effectiveness of $85 \%$ and dew point effectiveness of $65 \%$. Using potassium formate as a liquid desiccant, the dehumidification core was able to decrease the humid air relative humidity by about $17 \%$ with a dehumidification capacity of $733 \mathrm{~W}$ and humidity effectiveness of $47 \%$. The satisfactory preliminary testing results reported demonstrate the potential of using hollow fibre-based energy cores for cooling and dehumidification applications allowing technical, economic and environmental benefits compared to conventional cooling and dehumidification systems.

\section{Acknowledgement}

The authors gratefully acknowledge the special support of the 'Dean of Engineering Research Scholarship for International Excellence' Award 2011 from the Faculty of Engineering at the University of Nottingham.

\section{References}

[1] Afonso, C.F.A. (2006). Recent advances in building air conditioning systems. Applied Thermal Engineering 26(16):1961-71. 
[2] Anisimov, S., D. Pandelidis, and J. Danielewicz. (2014). Numerical analysis of selected evaporative exchangers with the Maisotsenko cycle. Energy Conversion and Management 88:426-41.

[3] Boributh, S., et al. (2012). Mathematical modeling and cascade design of hollow fiber membrane contactor for $\mathrm{CO} 2$ absorption by monoethanolamine. Journal of Membrane Science 401-402:175-89.

[4] Bui, V.A., L.T.T. Vu, and M.H. Nguyen. (2010). Modelling the simultaneous heat and mass transfer of direct contact membrane distillation in hollow fibre modules. Journal of Membrane Science 353(1-2):85-93.

[5] Cath, T.Y., et al. (2005). Membrane contactor processes for wastewater reclamation in space: Part I. Direct osmotic concentration as pretreatment for reverse osmosis. Journal of Membrane Science, 257(1-2):85-98.

[6] Cui, X., et al. (2014). Fundamental formulation of a modified LMTD method to study indirect evaporative heat exchangers. Energy Conversion and Management 88:372-81.

[7] Daou, K., R.Z. Wang, and Z.Z. Xia. (2006). Desiccant cooling air conditioning: a review. Renewable and Sustainable Energy Reviews 10(2):55-77.

[8] Das, R.S. and S. Jain. (2013). Experimental performance of indirect air-liquid membrane contactors for liquid desiccant cooling systems. Energy 57:319-25.

[9] Delfani, S., et al. (2010). Energy saving potential of an indirect evaporative cooler as a precooling unit for mechanical cooling systems in Iran. Energy and Buildings 42(11):2169-76.

[10] Dijkink, B.H., et al. (2004). Humidity control during bell pepper storage, using a hollow fiber membrane contactor system. Postharvest Biology and Technology 32(3):311-320.

[11] Duan, Z., et al. (2012). Indirect evaporative cooling: Past, present and future potentials. Renewable and Sustainable Energy Reviews 16(9):6823-50.

[12] Gabelman, A. and S.-T. Hwang. (1999). Hollow fiber membrane contactors. Journal of Membrane Science 159(1-2):61-106.

[13] Galabinski, M.J. (1999). Integrated water distribution/cooling pad system. Patent No. US5971370A.

[14] Hammoud, M., K. Ghali and N. Ghaddar. (2014). The Optimized Operation of a Solar Hybrid Desiccant/Displacement Ventilation Combined with a Personalized Evaporative Cooler. International Journal of Green Energy 11(2):141-60.

[15] Huang, S.-M. and M. Yang. (2013). Longitudinal fluid flow and heat transfer between an elliptical hollow fiber membrane tube bank used for air humidification. Applied Energy 112:75-82.

[16] Huang, S.-M., et al. (2013). Fluid flow and heat transfer across an elliptical hollow fiber membrane tube bank for air humidification. International Journal of Thermal Sciences 73:2837.

[17] Isetti, C., E. Nannei, and A. Magrini. (1997). On the application of a membrane air-liquid contactor for air dehumidification. Energy and Buildings 25(3):185-93.

[18] Johnson, D.W., C. Yavuzturk, and J. Pruis. (2003). Analysis of heat and mass transfer phenomena in hollow fiber membranes used for evaporative cooling. Journal of Membrane Science 227(1-2):159-71.

[19] Jradi, M and S. Riffat. (2014). Experimental investigation of a biomass-fuelled micro-scale tri-generation system with an organic Rankine cycle and liquid desiccant cooling unit. Energy 71:80-93.

[20] Kumar, A., A. Chaudhary and A. Yadav. (2014). The Regeneration of Various Solid Desiccants by Using a Parabolic Dish Collector and Adsorption Rate: An Experimental Investigation. International Journal of Green Energy 11(9):936-53. 
[21] Longo, G.A., and A. Gasprella. (2005). Experimental and theoretical analysis of heat and mass transfer in a packed column dehumidifier/regenerator with liquid desiccant. International Journal of Heat and Mass Transfer 48:5240-54.

[22] Lownestein, A. (2008). Review of liquid desiccant technology for HVAC applications. $H V A C \& R$ Research 14(6):819-39.

[23] Maheshwari, G.P., F. Al-Ragom, and R.K. Suri. (2001). Energy-saving potential of an indirect evaporative cooler. Applied Energy 69(1):69-76.

[24] Mansourizadeh, A. and A.F. Ismail. (2009). Hollow fiber gas-liquid membrane contactors for acid gas capture: A review. Journal of Hazardous Materials 171(1-3):38-53.

[25] Medlin, T.D. and H. Wilkins. (2000). Evaporative cooling system for cooling a poultry house. Patent No. 60793652000.

[26] Mei, L. and Y.J. Dai. (2008). A technical review on use of liquid-desiccant dehumidification for air-conditioning application. Renewable and Sustainable Energy Reviews 12(3):662-89.

[27] Mitsubishi. Applications of Hollow Fiber Membrane. April 21, 2014]; Available from: http://www.siww.com.sg/pdf/forum/JAPBF12_MitsubishiRayon.pdf.

[28] Oliveira, A.C., et al. (2000). Thermal performance of a novel air conditioning system using a liquid desiccant. Applied Thermal Engineering 20(13):1213-23.

[29] Pabby, A.K. and A.M. Sastre. (2013). State-of-the-art review on hollow fibre contactor technology and membrane-based extraction processes. Journal of Membrane Science 430:263-303.

[30] Peng, N., et al. (2012). Evolution of polymeric hollow fibers as sustainable technologies: Past, present, and future. Progress in Polymer Science 37(10):1401-24.

[31] Qi, R., L. Lu, and Y. Huang. (2014). Energy performance of solar-assisted liquid desiccant air-conditioning system for commercial building in main climate zones. Energy Conversion and Management 88:749-57.

[32] Qiu, G.Q., and S. B. Riffat. (2010). Experimental investigation on a novel air dehumidifier using liquid desiccant. International Journal of Green Energy 7:174-80.

[33] Rajabzadeh, S., et al. (2009). CO2 absorption by using PVDF hollow fiber membrane contactors with various membrane structures. Separation and Purification Technology 69(2):210-20.

[34] Riffat, S.B., S.E. James, and C.W. Wong. (1998). Experimental analysis of the absorption and desorption rates of $\mathrm{HCOOK} / \mathrm{H} 2 \mathrm{O}$ and $\mathrm{LiBr} / \mathrm{H} 2 \mathrm{O}$. International Journal of Energy Research 22(12):1099-103.

[35] She, X., Y. Yin, and X. Zhang. (2014). Thermodynamic analysis of a novel energy-efficient refrigeration system subcooled by liquid desiccant dehumidification and evaporation. Energy Conversion and Management 78:286-96.

[36] SpinTek. Hollow Fiber Membranes. April 19, 2014]; Available from: http://www.spintek.com/hollow-fiber-membranes.html.

[37] Uçkan, I., et al. (2013). Experimental investigation of a novel configuration of desiccant based evaporative air conditioning system. Energy Conversion and Management 65:606-15.

[38] Uçkana, I et al. (2014). Development Artificial Neural Network model for the prediction of the performance of a silica-gel desiccant wheel. International Journal of Green Energy. DOI:10.1080/15435075.2014.895733

[39] Yutong, L., and Y. Hongxing. (2010). Experimental Study Of An Open-Cycle Solar Collector/Regenerator Using Liquid Desiccant For Air Conditioning. International Journal of Green Energy 7:273-88. 
[40] Zhan, C., et al. (2011). Comparative study of the performance of the M-cycle counter-flow and cross-flow heat exchangers for indirect evaporative cooling - Paving the path toward sustainable cooling of buildings. Energy 36(12):6790-805.

[41] Zhang, L.Z. and N. Zhang. (2014). A heat pump driven and hollow fiber membrane-based liquid desiccant air dehumidification system: Modeling and experimental validation. Energy 65:441-51.

[42] Zhang, L.-Z., et al. (2012). Conjugate heat and mass transfer in a hollow fiber membrane module for liquid desiccant air dehumidification: A free surface model approach.

International Journal of Heat and Mass Transfer 55(13-14):3789-99. 


\section{List of Tables}

Table 1 Typical EER values for standard air conditioning techniques (Afonso 2006)

\begin{tabular}{l|cccccc}
\hline $\begin{array}{l}\text { Cooling } \\
\text { Technique }\end{array}$ & $\begin{array}{c}\text { Vapour } \\
\text { Compression }\end{array}$ & Absorption & Adsorption & Desiccants & Ejector & Thermoelectric \\
\hline $\begin{array}{l}\text { EER } \\
(\mathrm{Btu} / \mathrm{Wh})\end{array}$ & $7-17$ & $2-3.4$ & $0.7-2.7$ & $1.7-5.1$ & $0.9-2.7$ & $1.7-3.4$ \\
\hline
\end{tabular}

Table 2 Hollow fibre specifications

\begin{tabular}{l|c}
\hline Material & Polypropylene (PP) \\
\hline Outer Diameter $(\mu \mathrm{m})$ & $420 \sim 490$ \\
\hline Pore size $(\mu \mathrm{m})$ & $0.1 \sim 0.2$ \\
\hline Wall Thickness $(\mu \mathrm{m})$ & $40 \sim 50$ \\
\hline Membrane Porosity $(\%)$ & $45 \sim 55$ \\
\hline Water Flux (L/h.m $\left.{ }^{2}\right)$ & $100 \sim 120$ \\
\hline
\end{tabular}




\section{Figure Captions}

Fig. 1: Hollow fibre-based membranes (SpinTek)

Fig. 2: $\quad$ Hollow Fibre-based membrane applications (Mitsubishi)

Fig. 3: $\quad$ Experimental setup for the hollow-fibre based core

Fig. 4(a-b): $\quad$ (a) Hollow fibre bundle, (b) Fluid distribution network

Fig. 5(a-b): $\quad$ (a) Fluid pump, (b) AC air blower

Fig. 6(a-b): $\quad$ Variation of air (a) temperature and (b) relative humidity across the cooler at $30^{\circ} \mathrm{C}$ set temperature

Fig. 7(a-b): $\quad$ Evaporative cooler (a) cooling capacity and COP, (b) wet bulb and dew point effectiveness at $30^{\circ} \mathrm{C}$ set temperature

Fig. 8(a-b): $\quad$ Variation of air (a) temperature and (b) relative humidity across the cooler at $35^{\circ} \mathrm{C}$ set temperature

Fig. 9(a-b): $\quad$ Evaporative cooler (a) cooling capacity and COP, (b) wet bulb and dew point effectiveness at $35^{\circ} \mathrm{C}$ set temperature

Fig. 10(a-b): $\quad$ Variation of air (a) temperature and (b) relative humidity across the cooler at $45^{\circ} \mathrm{C}$ set temperature

Fig. 11(a-b): $\quad$ Evaporative cooler (a) cooling capacity and COP, (b) wet bulb and dew point effectiveness at $45^{\circ} \mathrm{C}$ set temperature

Fig. 12(a-b-c): $\quad$ Effect of inlet air temperature on the (a) temperature drop across the cooler, (b) cooling capacity and COP and (c) water temperature

Fig. 13(a-b-c-d): Variation of (a) air and desiccant temperature, (b) air relative humidity, (c) air enthalpy and dehumidifier cooling capacity and (d) humidity and enthalpy effectiveness at $30^{\circ} \mathrm{C}$ set temperature and $80 \%$ relative humidity

Fig. 14(a-b-c): $\quad$ Effect of the inlet air relative humidity on the (a) humidity drop across the dehumidifier, (b) cooling capacity and desiccant temperature and (c) humidity and enthalpy effectiveness

Fig. 15(a-b-c-d): Effect of inlet air temperature on the (a) air temperature drop, (b) relative humidity drop, (c) dehumidifier cooling capacity and the desiccant temperature and (d) dehumidifier effectiveness 